\title{
EKSPERIMENTASI MODEL PEMBELAJARAN TEAM ASSISTED INDIVIDUALIZATION (TAI) DAN THINK PAIR SHARE (TPS) DENGAN PENDEKATAN SAINTIFIK PADA MATERI FUNGSI DITINJAU DARI INTERAKSI SOSIAL
}

\author{
Heri Cahyono $^{1}$, Mardiyana $^{2}$, Dewi Retno Sari Saputro ${ }^{3}$ \\ ${ }^{123}$ Prodi Magister Pendidikan Matematika, FKIP Universitas Sebelas Maret Surakarta
}

\begin{abstract}
The aim of the research was to determine the effect of learning models on mathematics achievement viewed from student's social interaction. The learning models compared were TAI with scientific approach, TPS with scientific approach, and classical with scientific approach. The type of the research was a quasi experimental research with the factorial design of $3 \times 3$. The population were all eight grade students of Junior High School in Ngawi regency on academic year 2014/2015. The sample consisted of students of SMPN 3 Ngrambe, SMPN 2 Paron, and SMPN 2 Widodaren, which taken by using stratified cluster random sampling technique. The data of the research were collected through documentation, questionnaire, and test. The data was analyzed using unbalanced two-ways anova at the significance level of 0,05. Based on the data analysis, it can be concluded as follows. (1) TAI with scientific approach gives better mathematics achievement than TPS with scientific approach and classical with scientific approach, TPS with scientific approach and classical with scientific approach gives same mathematics achievement. (2) Students with high social interaction have better mathematics achievements than students with medium social interaction and low social interaction, while students with medium social interaction have better mathematics achievements than students with low social interaction. (3) For TAI with scientific approach, students with high and medium social interaction have the same mathematics achievements, and both have better mathematics achievement than low social interaction. For TPS with scientific approach, students with high social interaction have better mathematics achievement than students with medium and low social interaction, and students with medium and low social interaction have the same mathematics achievement. For classical with scientific approach, students with high social interaction have better mathematics achievement than students with medium social interaction, and both have the same mathematics achievement as students with low social interaction. (4) For students with high and low social interaction, all learning models gives the same mathematics achievement. For students with medium social interaction, TAI with scientific approach gives better mathematics achievement than TPS with scientific approach and classical with scientific approach, TPS with scientific approach and classical with scientific approach gives the same mathematics achievement.
\end{abstract}

Keywords: TAI with scientific approach, TPS with scientific approach, classical learning, social interaction, learning achievement.

\section{PENDAHULUAN}

Pendidikan merupakan salah satu modal untuk mencapai kemajuan bangsa, pendidikan juga merupakan salah satu modal untuk mencapai kemajuan bangsa dan merupakan media pengembangan ilmu pengetahuan dan teknologi. Sebagai ilmu dasar, matematika mempunyai peranan yang sangat penting terhadap perkembangan ilmu pengetahuan dan teknologi. Menurut Ignacio et al. (2006:16) mempelajari matematika merupakan suatu kebutuhan bagi setiap individu, kemajuan teknologi dan semakin pentingnya sarana komunikasi membuat orang perlu untuk beradaptasi dengan situasi baru yang timbul dalam perubahan sosial. Pelajaran matematika sampai saat ini masih 
dianggap sebagai suatu momok yang menakutkan bagi siswa. Menurut Ignacio et al. (2006:17) matematika merupakan ilmu yang penting dan oleh sebagian besar siswa matematika masih dianggap sulit, membosankan, tidak praktis dan abstrak. Sehingga perlu dikembangkan dan digunakan inovasi-inovasi yang menarik untuk mengatasi permasalahan tersebut.

Kabupaten Ngawi merupakan kabupaten yang prestasi belajar siswanya masih rendah dibandingkan dengan kabupaten lain di Jawa Timur. Berdasarkan hasil Ujian Nasional tahun 2013 mata pelajaran matematika menunjukkan urutan ke-38 dari 38 kabupaten/kota di Jawa Timur dengan nilai rata-rata 4,48 (BSNP 2013). Daya serap materi fungsi dari data BSNP pada tahun 2011, 2012, dan 2013 yaitu 70,76\%, 59,10\%, dan 43,94\%. Dari data tersebut prestasi belajar pada materi pokok fungsi dari tahun 2011 sampai tahun 2013 cenderung turun sehingga masih perlu ditingkatkan dan diperbaiki lagi. Salah satu faktor yang mempengaruhi prestasi belajar siswa adalah model pembelajaran yang digunakan saat proses pembelajaran. Pada kurikulum 2013 proses pembelajaran dapat menggunakan model pembelajaran diantaranya problem based learning, project based learning, discovery learning dan cooperative learning serta menggunakan pendekatan saintifik. Berdasarkan pengamatan peneliti pada kurikulum KTSP masih banyak guru yang mengajar dengan mengunakan model pembelajaran secara individu dan tidak berkelompok, sedang tingkat interaksi sosial antar siswa ketika pembelajaran masih tergolong baik, sehingga dalam penelitian ini dipilih model pembelajaran yang menggunakan kerjasama antar siswa dalam proses pembelajaran, maka peneliti memilih model pembelajaran kooperatif TAI (team assisted individualization) dan TPS (think pair and share) untuk digunakan dalam penelitian.

Model pembelajaran kooperatif TAI merupakan model pembelajaran yang berpusat pada siswa (student centered). Menurut Slavin and Cooper (dalam Tarim \& Akdeniz, 2007:78) model pembelajaran kooperatif TAI dapat digunakan di kelas saat pelajaran matematika. Model pembelajaran tersebut menggabungkan antara keberhasilan kelompok dengan tanggung jawab individu. Penelitian yang menggunakan model pembelajaran TAI juga dilakukan oleh Endang Hariyati (2013) diperoleh hasil bahwa siswa yang diberi model pembelajaran kooperatif TAI memberikan prestasi belajar matematika lebih baik daripada model pembelajaran PBL dan konvensional. Penelitian lain juga dilakukan oleh Tarim \& Akdeniz (2007) yang menyatakan "the pairwise comparisons showed that the TAI method had a more significant effect than the STAD method', yang berarti model pembelajaran TAI memberikan efek yang lebih signifikan daripada model pembelajaran STAD. 
Menurut Ibe (2009:26) pembelajaran TPS melibatkan para siswa dalam berpikir tentang respon pertama mereka, kemudian memungkinkan siswa untuk mendiskusikan ide-ide mereka dengan pasangan sebelum membagikan ide-ide mereka di kelas. Frank Lyman (dalam Trianto, 2007:61) mengemukakan bahwa model pembelajaran TPS merupakan suatu cara yang efektif untuk membuat variasi suasana pada pola diskusi kelas. Penelitian yang menggunakan model pembelajaran TPS dilakukan oleh Siti Amirah Budiastuti (2013) diperoleh hasil bahwa prestasi siswa yang diberi model pembelajaran TPS lebih baik daripada siswa yang diberi model pembelajaran konvensional. Penelitian lain juga dilakukan oleh Ofodu \& Lawal (2011) yang diperoleh hasil bahwa model pembelajaran koopetif TPS lebih unggul daripada model pembelajaran konvensional.

Model pembelajaran klasikal menurut Dimyati \& Mudjiono (2006:170) dengan jumlah siswa 10-45 orang seorang guru masih dapat membelajarkan siswa secara berhasil. Pembelajaran kelas berarti melaksanakan dua kegiatan sekaligus, yaitu (1) pengelolaan kelas dan (2) pengelolaan pembelajaran. Sebagai bentuk implementasi dari kurikulum 2013 pengelolaan pembelajaran menggunakan pendekatan saintifik.

Interaksi sosial menurut Shaw (dalam Mohammad Ali, 2004:87) merupakan suatu pertukaran antar pribadi yang masing-masing orang menunjukkan perilakunya satu sama lain dalam kehadiran mereka dan masing-masing perilaku mempengaruhi satu sama lain. Keberhasilan suatu pembelajaran tidak hanya ditentukan dari tingkat kecerdasan yang dimiliki dari masing-masing individu, namun juga ditentukan dari tingkat interaksi sosial antar individu karena pada proses pembelajaran siswa tidak selalu bisa bekerja sendiri dan cenderung berkelompok. Newman (dalam Adeyemi, 2008:696) menyatakan bahwa pembelajaran kooperatif didasarkan pada penciptaan, analisis dan struktur yang sistematis serta cara mengorganisasi interaksi sosial siswa di dalam kelas. Berdasarkan hal tersebut maka peneliti mengambil model pembelajaran kooperatif yang ditinjau dari interaksi sosial siswa.

Berdasarkan paparan tersebut penelitian ini bertujuan untuk mengetahui: (1) manakah yang lebih baik pembelajaran dengan menggunakan model TAI dengan pendekatan saintifik, TPS dengan pendekatan saintifik, atau klasikal dengan pendekatan saintifik dalam memberikan prestasi belajar matematika pada materi pokok fungsi, (2) manakah yang lebih baik dalam pembelajaran pada siswa dengan interaksi sosial tinggi, sedang, atau rendah dalam memberikan prestasi belajar matematika pada materi pokok fungsi, (3) pada masing-masing model pembelajaran, manakah yang lebih baik siswa dengan interaksi sosial tinggi, sedang, atau rendah, dalam memberikan prestasi belajar matematika pada materi pokok fungsi, (4) pada masing-masing tingkat interaksi sosial, 
manakah model pembelajaran yang lebih baik antara pembelajaran dengan menggunakan model TAI dengan pendekatan saintifik, TPS dengan pendekatan saintifik, atau klasikal dengan pendekatan saintifik dalam memberikan prestasi belajar matematika pada materi pokok fungsi.

\section{METODE PENELITIAN}

Jenis penelitian ini adalah eksperimental semu, dengan rancangan penelitian yang digunakan adalah rancangan faktorial $3 \times 3$. Populasi dalam penelitian ini adalah seluruh siswa kelas VIII SMP Negeri di Kabupaten Ngawi tahun pelajaran 2014/2015. Teknik pengambilan sampel menggunakan stratified cluster random sampling. Berdasarkan teknik sampling yang digunakan diperoleh bahwa sampel-sampel yang digunakan SMPN 3 Ngrambe mewakili sekolah kategori tinggi, SMPN 2 Paron mewakili sekolah kategori sedang, dan SMPN 2 Widodaren mewakili sekolah kategori rendah.

Variabel bebas dalam penelitian ini adalah model pembelajaran dan interaksi sosial siswa, sedangkan variabel terikatnya adalah prestasi belajar matematika. Metode pengumpulan data yang digunakan adalah metode angket, metode tes, dan metode dokumentasi. Metode angket dilakukan untuk memperoleh data interaksi sosial siswa dan metode tes digunakan untuk memperoleh data prestasi belajar matematika, sedangkan metode dokumentasi digunakan untuk memperoleh data sampel penelitian dan data kemampuan awal siswa. Data kemampuan awal diambil dari nilai UAS semester genap siswa sewaktu kelas VII. Data tersebut digunakan untuk uji prasyarat dilakukannya penelitian. Instrumen yang digunakan dalam penelitian ini berupa angket interaksi sosial dan tes prestasi belajar matematika pada materi fungsi yang sebelumnya telah diuji validitas dan reliabilitas instrumennya. Sebelum penelitian dilakukan, peneliti terlebih dahulu melakukan uji keseimbangan antara tiga kelompok populasi dengan uji anava satu jalan sel tak sama. Selanjutnya dilakukan pengujian hipotesis dengan menggunakan uji analisis variansi dua jalan sel tak sama.

\section{HASIL PENELITIAN DAN PEMBAHASAN}

Hasil uji keseimbangan pada penelitian menggunakan uji analisis variansi satu jalan sel tak sama. Hasil uji keseimbangan tersebut terangkum dalam Tabel 1.

Tabel 1. Rangkuman Analisis Variansi Satu Jalan Sel Tak Sama

\begin{tabular}{ccccccc}
\hline Sumber & $J K$ & $d k$ & $R K$ & $F_{o b s}$ & $F_{\alpha}$ & Keputusan \\
\hline Model Pemb. & 0,9940 & 2 & 0,4970 & 0,6219 & 3,0327 & $H_{0}$ diterima \\
Galat & 195,8082 & 245 & 0,7992 & - & - & \\
Total & 196,8022 & 247 & - & - & - & \\
\hline
\end{tabular}


Berdasarkan Tabel 1 dapat dilihat $F_{o b s}$ sebesar 0,6219 dan $F_{\alpha}$ sebesar 3,0327. Karena $F_{o b s}<F_{\alpha}$ maka $H_{0}$ diterima, sehingga disimpulkan bahwa populasi mempunyai kemampuan awal yang sama (seimbang).

Selanjutnya dilakukan uji hipotesis menggunakan anava dua jalan dengan sel tak sama. Hasil uji anava dua jalan sel tak sama ini terangkum dalam Tabel 2.

Tabel 2. Rangkuman Analisis Variansi Dua Jalan Sel Tak Sama

\begin{tabular}{lcccccc}
\hline \multicolumn{1}{c}{ Sumber Data } & $J K$ & $d k$ & $R K$ & $F_{\text {obs }}$ & $F_{\alpha}$ & Keputusan \\
\hline Model Pemb. (A) & 2842,18 & 2 & 1421,0912 & 9,0102 & 3,0336 & $H_{O A}$ ditolak \\
Interaksi Sosial (B) & 16684,11 & 2 & 8342,0563 & 52,8916 & 3,0336 & $H_{O B}$ ditolak \\
Interaksi (AB) & 2301,48 & 4 & 575,3688 & 3,6480 & 2,4094 & $H_{O A B}$ ditolak \\
Galat (G) & 37695,04 & 239 & 157,7198 & - & - & \\
Total (T) & 59522,81 & 247 & - & - & - & \\
\hline \multicolumn{1}{c}{ Dari hasil perhitungan $F_{\text {obs }}>F_{\alpha}$ untuk $H_{0 \mathrm{~A}}, H_{0 \mathrm{~B}}$ dan $H_{0 \mathrm{AB}}$, sehingga diperoleh }
\end{tabular}

kesimpulan sebagai berikut: 1) terdapat perbedaan pengaruh model pembelajaran terhadap prestasi belajar matematika siswa, 2) terdapat perbedaan pengaruh tingkat interaksi sosial siswa terhadap prestasi belajar matematika siswa, dan 3) terdapat interaksi antara model pembelajaran dan tingkat interaksi sosial siswa terhadap prestasi belajar matematika siswa.

Karena ketiga hipotesis ditolak, diperlukan uji lanjut pasca anava yakni uji komparasi ganda antar baris, antar kolom dan antar sel dengan metode Scheffe'. Sebelum dilakukan uji komparasi ganda antar baris, terlebih dahulu dihitung rerata marginalnya. Hasil perhitungan rerata tersebut disajikan dalam Tabel 3.

Tabel 3. Rerata Marginal Prestasi Belajar Matematika

\begin{tabular}{ccccc}
\hline \multirow{2}{*}{ Model Pembelajaran } & \multicolumn{3}{c}{ Kategori Interaksi Sosial } & Rerata \\
\cline { 2 - 4 } & Tinggi & Sedang & Rendah & Marginal \\
\hline TAI & 83,9126 & 72,0000 & 58,1607 & 70,5362 \\
TPS & 76,6662 & 57,9307 & 57,0003 & 62,4999 \\
Klasikal & 73,4845 & 58,5557 & 60,9197 & 63,4568 \\
Rerata Marginal & 78,1309 & 63,3687 & 58,6743 & \\
\hline
\end{tabular}

Tabel 3 digunakan untuk melihat rerata marginal dari masing-masing model pembelajaran dan kategori interaksi sosial siswa apabila dari perhitungan uji komparasi ganda berikut dinyatakan terdapat perbedaan yang signifikan.

Hasil uji ANAVA dua jalan sel tak sama menunjukkan $H_{0 A}$ ditolak, sehingga perlu dilakukan uji komparasi ganda antar baris. Rangkuman hasil uji rerata antar baris disajikan pada Tabel 4.

Tabel 4. Rangkuman Komparasi Ganda Antar Baris

\begin{tabular}{cccc}
\hline$H_{0}$ & $F_{\text {obs }}$ & $F_{\alpha}$ & Keputusan Uji \\
\hline$\mu_{1 *}=\mu_{2 *}$ & 17,0656 & 6,0672 & $H_{0}$ Ditolak \\
$\mu_{2 \cdot}=\mu_{3 .}$ & 0,2337 & 6,0672 & $H_{0}$ Diterima \\
$\mu_{1 *}=\mu_{3 \cdot}$ & 13,3292 & 6,0672 & $H_{0}$ Ditolak \\
\hline
\end{tabular}


Berdasarkan Tabel 4 diketahui terdapat perbedaan prestasi belajar matematika antara siswa yang diberi pembelajaran TAI dengan pendekatan saintifik dan TPS dengan pendekatan saintifik, serta yang diberi pembelajaran TAI dengan pendekatan saintifik dan klasikal dengan pendekatan saintifik. Dengan memperhatikan rerata marginalnya, dapat disimpulkan bahwa prestasi belajar matematika siswa yang diberi pembelajaran TAI dengan pendekatan saintifik lebih baik dibandingkan dengan siswa yang diberi pembelajaran TPS dengan pendekatan saintifik dan klasikal dengan pendekatan saintifik. Hal tersebut dikarenakan pada pembelajaran TAI anggota kelompok terdiri dari 4-5 siswa dan didalam kelompok siswa melaksanakan pembelajaran secara individu yang dibimbing oleh anggota kelompoknya sehingga siswa lebih mudah memahami materi pelajaran. Hasil ini sesuai dengan penelitian dari Awofala \& Nneji (2012) bahwa TAI lebih efektif dalam meningkatkan prestasi belajar matematika siswa, sehingga dapat berfungsi sebagai alternatif metode konvensional dalam pembelajaran matematika. Pada pembelajaran TPS dengan pendekatan saintifik dan klasikal dengan pendekatan saintifik pembelajaran dilakukan dengan berpasangan dan tidak berkelompok sehingga siswa lebih sulit memahami materi yang diajarkan karena pertukaran informasi tidak terlalu banyak.

Temuan lain adalah tidak terdapat perbedaan prestasi belajar matematika antara siswa yang diberi pembelajaran TPS dengan pendekatan saintifik dan klasikal dengan pendekatan saintifik, sehingga terdapat ketidaksesuaian antara hipotesis dengan hasil penelitian, hal ini dikarenakan tidak terdapat perbedaan yang signifikan antara tahapantahapan pembelajaran TPS dengan pendekatan saintifik dan pembelajaran klasikal dengan pendekatan saintifik, selain itu juga dimungkinkan karena data angket interaksi sosial siswa kurang obyektif sehingga prestasi yang dihasilkan juga tidak berbeda secara signifikan.

Hasil uji ANAVA dua jalan sel tak sama menunjukkan $H_{0 B}$ ditolak, sehingga perlu dilakukan uji komparasi ganda antar kolom. Rangkuman hasil uji rerata antar kolom disajikan pada Tabel 5.

Tabel 5. Rangkuman Komparasi Ganda Antar Kolom

\begin{tabular}{cccc}
\hline$H_{0}$ & $F_{o b s}$ & $F_{\alpha}$ & Keputusan Uji \\
\hline$\mu_{-1}=\mu_{-2}$ & 53,5756 & 6,0672 & $H_{0}$ Ditolak \\
$\mu_{-2}=\mu_{-3}$ & 6,3506 & 6,0672 & $H_{0}$ Ditolak \\
$\mu_{-1}=\mu_{-3}$ & 90,5218 & 6,0672 & $H_{0}$ Ditolak \\
\hline
\end{tabular}

Berdasarkan Tabel 5 diketahui terdapat perbedaan prestasi belajar matematika siswa dengan interaksi sosial tinggi, sedang, dan rendah. Dengan memperhatikan rerata marginalnya, dapat disimpulkan bahwa prestasi belajar matematika siswa dengan interaksi sosial tinggi lebih baik dibandingkan siswa dengan interaksi sosial sedang dan 
rendah, serta siswa dengan interaksi sosial sedang mempunyai prestasi belajar yang lebih baik dibandingkan siswa dengan interaksi sosial rendah. Hal ini dikarenakan siswa dengan tingkat interaksi sosial tinggi mampu mengatasi permasalahan pembelajaran dengan mendiskusikan/menanyakan masalah tersebut kepada guru maupun siswa lain sehingga diperoleh solusinya dan memperoleh lebih banyak ide, gagasan dan informasi baik dari guru maupun teman sebayanya.

Hasil uji ANAVA dua jalan sel tak sama menunjukkan $H_{0 A B}$ ditolak, sehingga perlu dilakukan uji komparasi rerata antar sel pada baris yang sama. Hasil uji rerata antar sel pada baris yang sama disajikan pada Tabel 6 .

Tabel 6. Rangkuman Komparasi Ganda Antar Sel pada Baris Sama

\begin{tabular}{cccc}
\hline$H_{0}$ & $F_{o b s}$ & $F_{\alpha}$ & Keputusan Uji \\
\hline$\mu_{11}=\mu_{12}$ & 12,5772 & 15,8182 & $H_{0}$ Diterima \\
$\mu_{11}=\mu_{13}$ & 54,3180 & 15,8182 & $H_{0}$ Ditolak \\
$\mu_{12}=\mu_{13}$ & 19,3962 & 15,8182 & $H_{0}$ Ditolak \\
$\mu_{21}=\mu_{22}$ & 27,3011 & 15,8182 & $H_{0}$ Ditolak \\
$\mu_{21}=\mu_{23}$ & 30,8179 & 15,8182 & $H_{0}$ Ditolak \\
$\mu_{22}=\mu_{23}$ & 0,1000 & 15,8182 & $H_{0}$ Diterima \\
$\mu_{31}=\mu_{32}$ & 18,0633 & 15,8182 & $H_{0}$ Ditolak \\
$\mu_{31}=\mu_{33}$ & 8,0463 & 15,8182 & $H_{0}$ Diterima \\
$\mu_{32}=\mu_{33}$ & 2,2540 & 15,8182 & $H_{0}$ Diterima \\
\hline
\end{tabular}

Berdasarkan Tabel 6 tidak terdapat perbedaan prestasi belajar matematika antara siswa dengan interaksi sosial tinggi dan sedang pada pembelajaran TAI dengan pendekatan saintifik, hal tersebut dikarenakan siswa belum dapat mengoptimalkan langkah-langkah pembelajaran yang harus diterapkan pada pembelajaran TAI dengan pendekatan saintifik, siswa belum bisa menyesuaikan diri sesuai dengan tujuan pembelajaran yang diterapkan pada kurikulum 2013 ini. Siswa terbiasa mendapatkan pembelajaran dengan cara mendengarkan guru dalam menyampaikan materi, serta menggunakan rumus yang diberikan tanpa mengetahui bagaimana cara untuk menyelesaikan suatu permasalahan berdasarkan ide dari pemahaman dan pengetahuan yang dimilikinya. Temuan lain adalah terdapat perbedaan prestasi belajar matematika antara siswa dengan interaksi sosial tinggi dan rendah, serta siswa dengan interaksi sosial sedang dan rendah. Dengan memperhatikan reratanya marginalnya, dapat disimpulkan bahwa pada pembelajaran TAI dengan pendekatan saintifik, prestasi belajar siswa tingkat interaksi sosial tinggi dan sedang lebih baik daripada rendah. hal tersebut dikarenakan siswa tingkat interaksi sosial rendah cenderung pasif dan pertukaran informasi yang diperoleh sedikit. 
Pada pembelajaran TPS dengan pendekatan saintifik terdapat perbedaan prestasi belajar matematika antara siswa dengan interaksi sosial tinggi dan sedang, serta siswa dengan interaksi sosial tinggi dan rendah. Dengan memperhatikan reratanya marginalnya, dapat disimpulkan bahwa pada pembelajaran TPS dengan pendekatan saintifik, prestasi belajar siswa tingkat interaksi sosial tinggi dan sedang lebih baik daripada rendah. Temuan lain adalah tidak terdapat perbedaan prestasi belajar matematika antara siswa dengan interaksi sosial sedang dan rendah, hal ini dikarenakan pada siswa interaksi sosial sedang siswa kurang mampu berinteraksi dengan baik dengan kelompoknya, sehingga prestasi belajarnya tidak berbeda signifikan dengan siswa tingkat interaksi sosial rendah.

Pada pembelajaran klasikal dengan pendekatan saintifik terdapat perbedaan prestasi belajar matematika antara siswa dengan interaksi sosial tinggi dan sedang. Dengan memperhatikan reratanya marginalnya, dapat disimpulkan bahwa pada pembelajaran klasikal dengan pendekatan saintifik, prestasi belajar siswa tingkat interaksi sosial tinggi lebih baik daripada sedang. Hal ini dikarenakan siswa tingkat interaksi sosial tinggi pada pembelajaran klasikal dengan pendekatan saintifik masih mampu menyampaikan ide/pendapat kepada guru atau teman saat presentasi, sehingga siswa dapat memahami materi dengan baik. Temuan lain adalah tidak terdapat perbedaan prestasi belajar matematika antara siswa dengan interaksi sosial tinggi dan rendah, serta siswa dengan interaksi sosial sedang dan rendah. Hal ini dikarenakan ditemukan data angket yang tidak obyektif pada siswa interaksi sosial tinggi, sehingga dimungkinkan mempengaruhi hasil penelitian.

Hasil uji ANAVA dua jalan sel tak sama menunjukkan $H_{0 A B}$ ditolak, sehingga perlu dilakukan uji komparasi rerata antar sel pada kolom yang sama dengan metode Scheffe'. Rangkuman hasil uji rerata antar sel pada kolom yang sama disajikan pada Tabel 7.

Tabel 7. Rangkuman Komparasi Ganda Antar Sel pada Kolom Sama

\begin{tabular}{cccc}
\hline$H_{0}$ & $F_{\text {obs }}$ & $F_{\alpha}$ & Keputusan Uji \\
\hline$\mu_{11}=\mu_{21}$ & 3,6547 & 15,8182 & $H_{0}$ Diterima \\
$\mu_{11}=\mu_{31}$ & 7,7528 & 15,8182 & $H_{0}$ Diterima \\
$\mu_{21}=\mu_{31}$ & 0,6896 & 15,8182 & $H_{0}$ Diterima \\
$\mu_{12}=\mu_{22}$ & 19,9042 & 15,8182 & $H_{0}$ Ditolak \\
$\mu_{12}=\mu_{32}$ & 18,5126 & 15,8182 & $H_{0}$ Ditolak \\
$\mu_{22}=\mu_{32}$ & 0,0365 & 15,8182 & $H_{0}$ Diterima \\
$\mu_{13}=\mu_{23}$ & 0,1259 & 15,8182 & $H_{0}$ Diterima \\
$\mu_{13}=\mu_{33}$ & 0,6998 & 15,8182 & $H_{0}$ Diterima \\
$\mu_{23}=\mu_{33}$ & 1,4362 & 15,8182 & $H_{0}$ Diterima \\
\hline
\end{tabular}


Berdasarkan Tabel 7 tidak terdapat perbedaan prestasi belajar matematika pada siswa dengan interaksi sosial tinggi, baik siswa yang diberi pembelajaran TAI dengan pendekatan saintifik, TPS dengan pendekatan saintifik, maupun klasikal dengan pendekatan saintifik. Hal tersebut dikarenakan pada siswa dengan interaksi sosial tinggi jika dikenai pembelajaran TAI dengan pendekatan saintifik siswa akan lebih aktif dalam berdiskusi dengan kelompoknya, sehingga diskusi kelompok dapat berjalan dengan efektif dan informasi yang diperoleh setiap individu akan lebih banyak. Apabila dikenai pembelajaran TPS dengan pendekatan saintifik diskusi dapat berjalan dengan baik karena setiap anggota kelompok dapat mengutarakan pendapat mereka dengan baik, serta pada pembelajaran klasikal dengan pendekatan saintifik siswa masih dapat mengikuti pembelajaran dengan baik karena siswa masih aktif bertanya kepada guru jika ada permasalahan dalam pembelajaran.

Pada siswa dengan interaksi sosial sedang, terdapat perbedaan prestasi belajar matematika antara siswa yang dikenai pembelajaran TAI dengan pendekatan saintifik dan TPS dengan pendekatan saintifik, serta pembelajaran TAI dengan pendekatan saintifik dan klasikal dengan pendekatan saintifik. Dengan memperhatikan reratanya marginalnya, dapat disimpulkan bahwa pada siswa dengan interaksi sosial sedang prestasi belajar matematika siswa dengan pembelajaran TAI dengan pendekatan saintifik lebih baik daripada pembelajaran TPS dengan pendekatan saintifik dan klasikal dengan pendekatan saintifik. Temuan lain adalah tidak terdapat perbedaan prestasi belajar matematika antara siswa yang dikenai pembelajaran TPS dengan pendekatan saintifik dan klasikal dengan pendekatan saintifik, hal ini dikarenakan pada siswa dengan interaksi sosial sedang siswa kurang mampu berinteraksi dengan baik dengan kelompoknya, sehingga prestasi belajarnya tidak berbeda signifikan dengan siswa yang dikenai pembelajaran klasikal dengan pendekatan saintifik.

Pada siswa dengan interaksi sosial rendah, tidak terdapat perbedaan prestasi belajar matematika baik pada siswa yang diberi pembelajaran TAI dengan pendekatan saintifik, TPS dengan pendekatan saintifik, maupun klasikal dengan pendekatan saintifik. Hal tersebut dikarenakan pada siswa dengan interaksi sosial rendah jika diberi pembelajaran TAI dengan pendekatan saintifik diskusi tidak dapat berjalan dengan baik karena siswa dengan tipe ini lebih suka menyelesaikan permasalahan secara individu daripada berkelompok, sedangkan jika diberi pembelajaran TPS dengan pendekatan saintifik maupun klasikal dengan pendekatan saintifik siswa cenderung bersikap pasif, jarang bertanya serta kurang bisa mengikuti pembelajaran dengan baik. 


\section{SIMPULAN DAN SARAN}

Berdasarkan hasil analisis dan pembahasan yang telah diuraikan sebelumnya, dapat disimpulkan sebagai berikut. 1) Pembelajaran dengan menggunakan model pembelajaran TAI dengan pendekatan saintifik lebih baik dibandingkan pembelajaran dengan menggunakan model pembelajaran TPS dengan pendekatan saintifik dan model pembelajaran klasikal dengan pendekatan saintifik dalam memberikan prestasi belajar matematika pada materi pokok fungsi, sedangkan pembelajaran dengan menggunakan model pembelajaran TPS dengan pendekatan saintifik sama baiknya dibandingkan pembelajaran dengan model pembelajaran klasikal dengan pendekatan saintifik dalam memberikan prestasi belajar matematika pada materi pokok fungsi. 2) Siswa tingkat interaksi sosial tinggi lebih baik dibandingkan dengan siswa tingkat interaksi sosial sedang dan rendah dalam memberikan prestasi belajar matematika pada materi pokok fungsi, sedangkan siswa tingkat interaksi sosial sedang lebih baik dibandingkan dengan siswa tingkat interaksi sosial rendah dalam memberikan prestasi belajar matematika pada materi pokok fungsi. 3) Pada model pembelajaran TAI dengan pendekatan saintifik siswa dengan tingkat interaksi sosial tinggi dan sedang mempunyai prestasi belajar yang sama pada pembelajaran matematika materi pokok fungsi. Selanjutnya siswa dengan tingkat interaksi sosial tinggi dan sedang mempunyai prestasi belajar matematika yang lebih baik daripada siswa dengan tingkat interaksi sosial rendah pada pembelajaran matematika materi pokok fungsi, pada model pembelajaran TPS dengan pendekatan saintifik siswa dengan tingkat interaksi sosial tinggi mempunyai prestasi belajar matematika yang lebih baik daripada siswa tingkat interaksi sosial sedang dan rendah pada pembelajaran matematika materi pokok fungsi, selanjutnya siswa tingkat interaksi sosial sedang dan rendah mempunyai prestasi belajar matematika yang sama baiknya pada pembelajaran matematika materi pokok fungsi, pada model pembelajaran klasikal dengan pendekatan saintifik prestasi belajar matematika siswa tingkat interaksi sosial tinggi lebih baik daripada siswa tingkat interaksi sosial sedang pada pembelajaran matematika materi pokok fungsi. Selanjutnya siswa tingkat interaksi sosial tinggi dan sedang mempunyai prestasi belajar yang sama baiknya dengan siswa tingkat interaksi sosial rendah pada pembelajaran matematika materi pokok fungsi. 4) Pada siswa tingkat interaksi sosial tinggi penggunaan model pembelajaran TAI dengan pendekatan saintifik, model pembelajaran TPS dengan pendekatan saintifik, dan model pembelajaran klasikal dengan pendekatan saintifik memberikan prestasi belajar matematika yang sama pada pembelajaran matematika materi pokok fungsi, pada siswa tingkat interaksi sosial sedang penggunaan model pembelajaran TAI dengan pendekatan saintifik lebih baik daripada model pembelajaran TPS dengan pendekatan saintifik dan model pembelajaran klasikal 
dengan pendekatan saintifik pada pembelajaran matematika materi pokok fungsi, selanjutnya penggunaan model pembelajaran TPS dengan pendekatan saintifik dan model pembelajaran klasikal dengan pendekatan saintifik memberikan prestasi belajar matematika yang sama baiknya pada pembelajaran matematika materi pokok fungsi, pada siswa tingkat interaksi sosial rendah penggunaan model pembelajaran TAI dengan pendekatan saintifik, model pembelajaran TPS dengan pendekatan saintifik, dan model pembelajaran klasikal dengan pendekatan saintifik memberikan prestasi belajar matematika yang sama baiknya dalam pembelajaran matematika materi pokok fungsi.

Saran terkait hasil penelitian tersebut adalah guru hendaknya selalu memperluas wawasannya mengenai model pembelajaran, seperti model pembelajaran TAI dan TPS dengan pendekatan saintifik untuk diterapkan dalam penerapan proses pembelajaran. Guru juga sebaiknya juga memperhatikan tingkat interaksi sosial yang dimiliki siswa agar proses pembelajaran dapat berlangsung dengan baik dan menghasilkan prestasi belajar yang maksimal. Bagi peneliti lain, diharapkan dapat meneruskan atau mengembangkan penelitian ini dengan variabel/model lain yang lebih inovatif, sehingga dapat meningkatkan kualitas pembelajaran khususnya dan pendidikan pada umumnya.

\section{DAFTAR PUSTAKA}

Adeyemi, B. A. 2008. Effects of cooperative learning and problem-solving strategies on Junior Secondary School Students' Achievement in Social Studies. Electronic Journal of Research in Educational Psychology. Vol. 6 (3) No. 16: 691-708.

Awofala, A. O. A and Nneji, L. M. 2012. Effect of Framing and Team Assisted Individualized Instructional Strategies on Students' Achievement in mathematics. Journal of the Science Teachers Association of Nigeria. Vol. 47 No. 1: 1-9

Badan Standar Nasional Pendidikan (BSNP). 2013. Laporan Hasil Ujian Nasional Tahun Pelajaran 2012/2013.

Dimyati \& Mudjiono. 2006. Belajar dan Pembelajaran. Jakarta: Rineka Cipta

Endang Hariyati. 2013. Efektivitas Model Pembelajaran Kooperatif Tipe Team Assisted Individualization (TAI) dan Problem Based Learning (PBL) Pada Prestasi Belajar Matematika Ditinjau Dari Multiple Intelligences Siswa SMP Kabupaten Lampung Timur Tahun Pelajaran 2012/2013. Tesis: Universitas Sebelas Maret Surakarta.

Ibe, H. N. 2009. Metacognitive Strategies on Classroom Participation and Student Achievement in Senior Secondary School Science Classrooms. Science Education International. Vol. 20 No. 1/2: 25-31.

Ignacio, N.G., Blanco Nieto, L.J. \& Barona, E.G. 2006. The Affective Domain In Mathema Tics Learning. International Electronic Journal of Mathematics Education. Vol. 1 No. 1: 16-32. 
Mohammad Ali. 2004. Psikologi Remaja. Jakarta: Bumi Aksara.

Ofodu, G. O. \& Lawal, R. A. 2011. Cooperative Instructional Strategies and Performance Levels of Students in Reading Comprehension. International Journal of Emerging Sciences. Vol. 3 No. 2: 103-107.

Siti Amirah Budiastuti. 2013. Eksperimentasi Model Pembelajaran Kooperatif Think Pair Share dan Team Assisted Individualization Pada Materi Trigonometri Ditinjau Dari Minat Belajar Matematika Siswa SMK di Kabupaten Ponorogo Tahun Pelajaran 2011/2012. Tesis: Universitas Sebelas Maret Surakarta.

Tarim, K. \& Akdeniz, F. 2007. The effects of cooperative learning on Turkish elementary students' mathematics achievement and attitude towards mathematics using TAI and STAD methods. Journal of Educational Studies in Mathematics. Vol. 67 No. 1: 77-91.

Trianto. 2007. Model-model pembelajaran inovatif berorientasi kontruktivistik. Jakarta: Prestasi Pustaka. 